\title{
Montoneras Populares durante la gestación de la República, Chile: 1810-1820¹
}

\author{
Popular Guerrillas at the Birth of the Republic: \\ Chile, 1810-1820
}

Leonardo León

Universidad de Chile

Se examina el movimiento social que se produjo en Chile central durante la década 1810-1820, analizando con particular atención el surgimiento de las montoneras populares que, de modo simultáneo con monarquistas y mapuches, desafiaron el proyecto republicano. Cipriano Palma, José María Zapata, Pablo Pincheira y Vicente Benavides, entre otros, emergen como los líderes de las guerrillas plebeyas que obligaron al retroceso de las fuerzas revolucionarias desde Concepción hacia la capital, junto con centenares de sujetos anónimos que, bajo el disfraz de asaltantes, ladrones y bandidos, asolaron villas y estancias. Se plantea que los grupos subalternos sacaron ventaja del vacío de poder que generó la Revolución, para levantarse en armas y, de esa manera, resistieron la instalación de un régimen político monopolizado por los criollos. El relato constituye una visión revisionista de la historiografía de la época, elaborada en torno a las hazañas de la elite y del Estado.

PALABRAs Clave: Independencia; Montoneras; Caudillos; Represión.

This article deals with the social movement that erupted in Central Chile during the 1810-1820 decade, examining the upsurge of popular montoneros who, contemporary to the monarchists and free Mapuche Indians resistance, challenged the Republican project. Cipriano Palma, José María Zapata, Pablo Pincheira y Vicente Benavides, amongst others, emerge as the leaders of those plebeian guerillas that forced the displacement of revolutionary forces from Concepción to Santiago; it also quotes official reports of hundreds of marauders, thieves and bandits who runsacked resources from local villages and the countryside. It postulates that subaltern social groups took advantage of the power vacuum created by the 1810 Revolution, took up arms and, thus armed, withstood the installation of a political regime monopolised by the creole aristocracy. This account also defies official history, which is centered exclusively around the facts derived from the actions of the elite and the State.

KEYwORDS: Independence; Montoneras, Caudillos; Repression.

1 Este trabajo se ha realizado en el marco del proyecto Fondecyt 1090144: Montoneras populares y rebelión del peonaje en la gestación de la República: Chile, 1810-1835. Mis agradecimientos a los licenciados Marisol Videla y Fernando Ulloa por su colaboración en la investigación llevada a cabo en el Archivo Nacional. 
«Fusile U. a todo malvado; destrúyase de una vez esta feroz especie indigna de cuantas sustenta la Madre Patria, y continúe usted llenándose de gloria». ${ }^{2}$ Estas palabras, escritas en 1817 por el general Bernardo O'Higgins, no se referían al castigo que debía darse a los soldados del rey. Su objetivo eran los 'bandidos y malhechores' que componían las montoneras plebeyas que afloraron en el reino durante los años de vacío político que dejó la Revolución de 1810. Monarquistas y mapuches han sido descritos como la gran muralla humana contra la cual chocaron los republicanos en el sur de Chile; ${ }^{3}$ lo que no se ha mencionado con igual fuerza son las guerrillas populares que, siguiendo su propio derrotero, se levantaron contra las autoridades y asolaron Chile central. «La calamitosa situación de estos pueblos», escribió O'Higgins después de la victoria de Chacabuco en febrero de 1817, «con el desenfreno de estos bandidos que uniéndose a las cuadrillas y a la sombra de las alteraciones políticas, atacan la seguridad individual y pública, instan por un castigo pronto y ejemplar». ${ }^{4} \mathrm{El}$ saldo que cosecharon los regimientos patriotas después de Chacabuco no fue el aplauso de la plebe ni la tranquilidad con que soñaban sus líderes; por el contrario, la guerra dejó al país al borde de una rebelión social.

La Independencia en Chile fue más compleja que lo planteado hasta aquí por el relato historiográfico. ${ }^{5}$ La revolución debió lidiar, en una primera fase, con la oposición regional centrada en Concepción y con las luchas internas que desgastaron su liderazgo. ${ }^{6}$ Pero también se enfrentó a la apatía de la plebe urbana y a la fuga del peonaje rural de las partidas de reclutas. Posteriormente, experimentó la masiva deserción de los grupos populares de los regimientos de la Patria. ${ }^{7}$ Desde la instalación de la Primera Junta Nacional de Gobierno en septiembre de 1810, Chile presenció un enfrentamiento que tenía las características de una guerra civil más que de una genuina revolución. En 1814, se marcó el inicio de una segunda fase con el desembarco de tropas provenientes del Perú que, engrosadas por contingentes sureños, se desplazaron hacia Santiago, donde entraron victoriosas a

2 Bernardo O’Higgins al comandante de la Plaza de Cauquenes, Concepción, 16 de agosto de 1817, en Archivo Histórico Nacional, Ministerio de Guerra (ANMG) 28, 301.

3 Bengoa, 1985, 135; Pinto, 2000, 48.

4 ANMG, 7, 54, O'Higgins a Ignacio Zenteno, Talca, 22 de abril de 1817.

5 Para un relato global del proceso de la Independencia sigue vigente la obra clásica de Barros Arana, VI-XIV; Encina, 1984, 7-18; Collier, 1977; Jocelyn-Holt, 1992; Salazar, 2005; Pinto y Valdivia 2009.

6 Cartes, 2010.

7 León, 2002, 251-297; 2008, 33-66; 2009, 75-102; 2010, 107-132. 
comienzos de octubre. ${ }^{8}$ Tres años duró el periodo de Restauración monárquica. Después de febrero de 1817, el escenario militar fue tomado por tres fuerzas beligerantes: el ejército patriota, el ejército monarquista y el 'ejército' plebeyo. Este último estaba constituido por un conglomerado de desertores, bandidos y criminales quienes, uniendo sus fuerzas, sus experiencias militares y los armamentos que poseían, acosaron a los regimientos regulares, asolaron las aldeas y sembraron el terror en Chile central. ${ }^{9}$

La hipótesis de este trabajo plantea que la revolución en Chile no fue solamente un movimiento aristocrático que aspiraba a la Independencia de España y del virreinato, sino que tuvo su contrapartida en la erupción de un movimiento social popular que resistió, con las armas en las manos, la instalación del régimen republicano. ${ }^{10}$ Para desarrollar esta hipótesis se propone reconocer el protagonismo que tuvieron las fuerzas plebeyas en la evolución de la gesta independista durante la primera década revolucionaria. El punto de partida de este trabajo gira en torno a varias interrogantes. ¿Qué sucedió con los desertores que abandonaron los regimientos 'patriotas' y realistas durante la guerra? ¿Volvieron a sus labores agrícolas o más bien se transformaron en bandidos armados? ¿De que manera la experiencia ganada en los campos de batalla les sirvió para organizarse? Si una parte de los desertores se tornó en guerrilleros, ¿Cuáles fueron los procesos que gestaron su transformación? ¿De qué manera influyó sobre ellos la tradición de vagabundaje, ociosidad e insumisión de sus antepasados?

En este artículo confluyen diversas corrientes historiográficas centradas en el estudio de lo 'popular'. Respecto del marco teórico se tiene presente una doble subalternidad, en tanto que los sectores populares de Chile central estaban subordinados a quienes se sentían sometidos por el imperio hispano. En este trabajo se intenta ir más allá del relato patricio para rescatar esas voces subalternas, menos audibles, que han quedado silenciadas. ${ }^{11}$ Tarea nada fácil de cumplir pues los registros disponibles son insuficientes; meros fragmentos que deben ser hilvanados con paciencia, traspasando el filtro de la dominación. Lo cierto es que la historia de la plebe chilena se sitúa en un horizonte omitido por el relato republicano y que se funde con lo pintoresco y lo parroquial. Este trabajo recoge esas palpitaciones, pero también se escribe desde la perspectiva que proporciona el concepto de

8 Guerrero, 2002.

9 Vicuña Mackenna, 1972.

10 Eyzaguirre, 1957; Meza, 1958; Villalobos, 1961.

11 Guha, 2002, 20. 
'economía moral', en la medida que los 'guerrilleros populares' reflejaron un clamor de justicia de índole más general ${ }^{12}$. Desde la microhistoria, se enfoca la mirada sobre aquellos incidentes que urdieron la guerra y se subraya el rol de los sujetos, procurando demostrar que lo 'popular' existió más allá del 'gesto' que le suprimió. ${ }^{13}$ Se trata de fijar la mirada en esa vasta masa de piel obscura que conformaban «las clases inferiores del pueblo de Chile». ${ }^{14}$ Sujetos que no sólo fueron despojados de su historia sino también de su memoria. Sin perder de vista el movimiento global de la Independencia, se propone llevar a cabo un enfoque particular de la resistencia militar de los grupos populares y resaltar su impacto en la gestación de la República. ${ }^{15}$ También se intenta replantear, críticamente, el relato hasta aquí desarrollado por la historiografía oficial. «Necesitamos poner al descubierto la historia de la 'gente sin historia'». ${ }^{16}$

Antes de proseguir es necesario señalar que el patrón que asumió la guerra de la Independencia en Chile no se distinguió totalmente del cariz que adquirió el conflicto en otras partes del continente. John Lynch identificó, en la década de 1970, tanto la naturaleza aristocrática del movimiento emancipador como el peligro de una guerra social, producto de la presión que ejercían las castas, indios y mestizos. ${ }^{17}$ Pero poco podía hacerse cuando la guerra creó los vacíos de poder que permitieron el afloramiento de viejas disputas étnicas, fraccionales y sociales. ${ }^{18}$ Por ese motivo, la simple traducción de la Independencia como una guerra nacional que dividió a los españoles de los americanos luce ahora como una simplificación ingenua que ha sido superada; actualmente se habla de movimientos sociales paralelos, marginales o subalternos, que desde diferentes rincones asediaron el proyecto republicano. «El título de mi libro», escribió Eric Van Young, «tiene como fuente de inspiración esa intrahistoria: la 'otra' rebelión (con todas las connotaciones contemporáneas del término) distinta de la historia 'oficial' ...». ${ }^{19}$ En este texto se notará la ausencia de datos 'duros' que permitan descubrir las motivaciones de los protagonistas plebeyos,

2 Thompson, 2002, 365; Hobsbawm, 2001.

13 Ginzburg, 1981, 15.

14 Barros Arana, VII, 316.

15 Goicovich, 2000, 59-70; Salazar, 2003; Rojas, 2008.

16 Wolf, 2009, 10.

17 Lynch, 1973, 20. Gruzinski.

18 O'Phelan, 1988; 1995; Stern; Fisher, 2006; Phelan, 1978; McFarlane, 1995, 313-338;

19 Van Young, 2001, 28. 
pero los archivos son parcos y escasos en ese sentido. Se puede decir que queda pendiente la tarea de explorar las diversas dimensiones del alzamiento de la plebe armada, pero lo importante era iniciar el relato de esa 'otra rebelión' en el confín del Mundo.

\section{Los grupos subalternos y la Revolución Autonomista}

El saldo cosechado por las masas latinoamericanas después de la Emancipación fue bastante magro. ${ }^{20}$ En Chile, los beneficios para el populacho fueron casi inexistentes. No podía ser de otra manera, especialmente si se tiene en cuenta que uno de los principales enemigos de la naciente República fue la plebe. Décadas de vagabundaje, cuatrerismo y bandolerismo en Chile central permitieron a la elite elaborar una imagen negativa del populacho que, además, era visto como la principal amenaza contra el orden social. ${ }^{21}$ La ola de criminalidad y los desordenes registrados durante los preámbulos de 1810, corroboraron esa percepción..$^{22}$ Globalmente, como lo señalaron algunos autores de la época, la plebe se asemejaba a una peste que convenía extirpar. De acuerdo a Manuel de Salas, los sectores populares vivían en «la pobreza extrema, la despoblación asombrosa, los vicios, la prostitución, la ignorancia y todos los males que son efecto necesario del abandono de tres siglos». ${ }^{23}$ Estas expresiones no fueron aisladas. Incluso los miembros de la Junta Revolucionaria dejaron estampadas sus versiones negativas de la plebe: «Os halláis sin industria y sin ocupaciones para subsistir; por esto no podéis ser unos hombres libres, pero vagos». ${ }^{24}$

La Revolución de 1810 no cambió esta representación. Por el contrario, la apatía de la plebe, su continua evasión del reclutamiento y la deserción masiva, demostraron que los sectores populares no hicieron suyo el ideario republicano. Si algo cambió, fue el modo de operar de los 'capitanes de la plebe', título con que se conocía a los líderes populares, quienes mostraron una creciente osadía en sus acciones. En 1813, apenas dos años después de instalado el gobierno nacional, las autoridades se quejaban de «la extraordinaria frecuencia con que en esta ciudad y sus campos se come-

\footnotetext{
20 Terán, 1999, 273-294; Tutino, 295-322; Valencia Llanos, 34-55; Quintero, 327-346;

21 Góngora, 1968; Araya, 1999.

22 León, 2007, 337- 368.

23 Salas, 46; para un recuento más detallado de estas visiones, Villalobos, 1960.

24 Talavera, 3, 537.
} 
ten salteos, robos, asesinatos y otros excesos, que atacan inmediatamente la seguridad individual, y perturban la quietud...». ${ }^{25}$ La movilización de las autoridades para castigar a los criminales no logró contener los brotes de bandolerismo. «Lo que únicamente abunda», escribió José Miguel Carrera a O’Higgins, en noviembre de ese año, «son partidas de ladrones que impunemente saquean las casas de algunos vecinos indefensos». ${ }^{26}$ En esos años de incertidumbre, el peonaje gavillero se convirtió en amo del mundo rural en medio de los estertores de una patria monárquica que moría y la tenue luz del amanecer republicano. Finalmente, a fines de 1813, la plebe hizo su aparición en los campos de batalla. «Los que caían en manos de los huasos eran degollados...», escribió Carrera al describir la precipitada retirada de sus tropas desde el sitio de Chillán. ${ }^{27}$ Asimismo, la guerra civil forzó el desplazamiento de gruesos contingentes de pobres, en tanto que otros se hicieron bandidos para sobrevivir. ${ }^{28}$ Mientras eso ocurría en las campiñas, la plebe urbana no permaneció inactiva; aprovechando que las autoridades tenían puesta su atención en los campos de Marte, los habitantes de los arrabales hicieron sentir su presencia en los recintos poblados.

"La multiplicación de robos y salteos llama toda la atención del gobierno por la seguridad individual de los ciudadanos", observaba Hilarión de la Quintana a mediados de junio de 1817, "se observa con dolor que las penas comunes no bastan á contener este crimen precursor de otros delitos mas atroces. Por tanto se declara, que todo el que robase de quatro pesos para arriba, será pasado por las armas, y el ladrón de menos cantidad sufrirá doscientos azotes y seis años de trabajo en las obras públicas". ${ }^{29}$

El populacho demostraba su indiferencia hacia los bandos que se disputaban el poder en Chile, pero al mismo tiempo tomaba ventaja de la anarquía creada por la guerra para revitalizar su tradición de bandidaje. Tampoco cambiaron las cosas cuando, a mediados de 1816, el gobierno Restaurador se preparó para impedir la invasión de los regimientos de San Martín y O’Higgins provenientes de Cuyo. En ese momento reemergieron

25 La Aurora de Chile, 11 de marzo de 1813.

26 Archivo de don Bernardo O'Higgins (ABO), 1, 270, Carrera a O'Higgins, Concepción, 3 de noviembre de 1813 .

27 Carrera, Diario, 161.

28 ANMG, 5, s. f., «El Síndico procurador de la Colonia de Osorno y demás pobladores al Director Supremo, Osorno, 15 de agosto de 1811».

29 «Bando de don Hilarión de la Quintana, coronel de los ejércitos de la Patria y Director Supremo Delegado de Chile», Gazeta de Santiago de Chile, Santiago, 19 de julio de 1817. Sobre los castigos, ver Arancibia et al, 131-150; Cornejo et al, 2003; Fernández, 2000, 75-110. 
los plebeyos armados. Así se desprende de las instrucciones que envió el gobernador Marcó del Pont a Joaquín Magallar:

El Cabildo y vecindario de San Fernando ha solicitado vuelva usted a la comandancia de aquel partido por necesitar de su celo y actividad para la persecución y exterminio de salteadores y ladrones ... como los partidos de Curicó y Maule padecen el mismo daño y los facinerosos se fugan de unos a otros, extenderá usted a todos sus providencias. ${ }^{30}$

Las instrucciones de Marcó reflejaron un grado de alarma que no correspondía a la magnitud del peligro; sus disposiciones incluían el desplazamiento de una compañía de Dragones «para tomar los caminos y guaridas donde pueda lograrse la captura de esos delincuentes». Si bien no se especificó el número de los alzados, el mismo Marcó señaló que

se han acuadrillado crecido número de facinerosos y conspiradores armados, abrigados en las cordilleras de Colchagua hasta Maule, de donde hacen sus incursiones y salteos con la mayor insolencia a los caminantes y poblados de esos partidos y se sabe por declaraciones de otros que se halla reunido a ellos uno de los famosos insurgentes de esta capital, hijo de don Carlos Rodríguez, prófugo, enviado de Mendoza por el gobernador San Martín para revolucionar y confederar a sus intentos a esas gentes. ${ }^{31}$

La mención de Manuel Rodríguez como jefe de las montoneras dio inicio a un mito de larga duración que concibió sus acciones como una genuina «insurrección social». ${ }^{32}$ La comunicación del gobernador también apuntó hacia un nuevo elemento que el relato histórico no tuvo en cuenta: la potencial alianza entre patriotas, montoneros populares y araucanos. ${ }^{33}$ «Sobre todo tome las mayores precauciones para que Rodríguez, ni su coligados, no se introduzcan en las reducciones, señaladamente en comunicación con el indio Venancio u otros díscolos de los Butalmapus». ${ }^{34}$ Tanto el gobernador como sus asesores comenzaron a ver en cada chileno un enemigo. A comienzos de noviembre de 1816, alarmado por los rumores que llegaron a la capital de que los montoneros se habían tomado «a viva fuer-

30 Archivo Nacional Histórico, Ministerio del Interior (ANMI) 26, 232, el gobernador de Chile don Francisco Marcó del Pont al capitán de Dragones don Joaquín Magallar, Santiago, 28 de mayo de 1816.

31 Ibidem, 259, Marcó del Pont al intendente de Concepción, Santiago, 12 de septiembre de 1816.

32 Pinto y Valdivia, 98; ver también León, 2010.

33 Casanova, 2000; Gallardo, 2001, 121; Marimán et al, 2006, 83.

34 ANMI 26, 259, Marcó del Pont al intendente de Concepción, Santiago, 12 de septiembre de 1816. Butalmapu es una voz mapuche que significa País Grande. 
za» la hacienda de Cumpeo, Marcó consagró la imagen de los guerrilleros. «Todos aquellos que sabiendo el paradero de los expresados José Miguel Neira, don José Manuel Rodríguez y demás de su comitiva no dieren pronto aviso a las justicias más inmediatas, sufrirán también la pena de muerte...». ${ }^{35}$ Este Bando, más que ninguna acción de Rodríguez, le otorgó un lugar entre los próceres republicanos. La recompensa de mil pesos que se ofreció por su cabeza y el indulto a quienes le capturaran «de cualquier delito que hayan cometido, aunque sean los más atroces», terminó por reafirmar la aparente peligrosidad del guerrillero. ${ }^{36}$ Según Barros Arana, la persecución envalentonó a Neira y sus seguidores, quien «siguió operando animosamente en aquella región, mientras Rodríguez iba a preparar empresas más audaces todavía en las mismas cercanías de Santiago». Rodríguez y algunos peones asaltaron la aldea de Melipilla. Allí, como parece haber sido habitual, los guerrilleros se olvidaron de la guerra. «Los montoneros pasaron todo el día en fiesta y diversión, sin entregarse, sin embargo, a los actos de violencia que era natural esperar de tales circunstancias». ${ }^{37}$ Para quienes seguían de cerca la situación, el país daba la apariencia de estar invadido por centenares de montoneros republicanos, a pesar que las operaciones guerrilleras fueron de escasa magnitud y sin mayor trascendencia bélica. Frente al peligro que representaban Rodríguez y Neira, que era más imaginario que real, se impuso la pena de muerte,

contra los que hicieren o resistencia con arma blanca a los que los persiguiesen, como a los que hallaren en número de tres corriendo el campo con armas, en reuniones sospechosas, en aclamaciones por la Patria... la misma pena impondrán a cuantos resultaren haber sido sabedores de la residencia de ladrones, salteadores y comitivas o del lugar de tránsito de aquellos y no dieren parte ${ }^{38}$.

En los días que siguieron a este Bando, la localidad de San Fernando fue amagada por una guerrilla encabezada por Francisco Salas y Feliciano Silva, provocando aún mayor alarma en el gobierno que dispuso de modo perentorio:

La pena de muerte será aplicada a cuantos se hallen con el delito de cargar armas, saquear y robar y demás que se advierten, e incluidos en ella cuanto los abriguen y

35 Bando de Francisco Casimiro Marcó del Pont, Santiago, 7 de noviembre de 1816, citado en Barros Arana, X, 318.

36 Idem.

37 Barros Arana, X, 342.

38 Bando de Marcó del Pont, 5 de enero de 1817, Ibidem, 345. 
los oculten. A más, sus casas se incendiarán, y hasta su memoria se borrará. Castíguese de un modo que la ejecución escarmiente, y no viva quien es infiel a su Rey y a la causa que se sostiene... óigase el cuchillo donde la paz no se escuchó, y queden por su infamia en las sombras del delito, así los secuaces de él como los auxiliares y protectores. ${ }^{39}$

Demostrando una tremenda incapacidad política, Marcó puso al populacho en su contra. Su gobierno sería recordado como la gestión de un hombre déspota, amanerado y aristocrático; la suerte de Neira fue igualmente infausta. Mientras el ejército patriota enfrentó a los monarquistas en Chacabuco, Neira desplazó a sus hombres hacia Talca, a la espera del contingente que Ramón Freire debía introducir en Chile central. Freire, interesado en restablecer el orden después de la derrota de los monarquistas, dictó un decreto que condenaba a muerte a los ladrones.

Uno o dos días después Neira fue sorprendido in fraganti en un atentado de esta clase. Había asaltado la casa de unas pobres mujeres en los suburbios de la ciudad, estropeado a éstas y robádose los pocos objetos de algún valor que poseían. Sometido inmediatamente a un consejo de guerra, y condenado a muerte, Neira fue fusilado en la madrugada del día siguiente en castigo de sus faltas y para escarmiento de aquéllos de sus compañeros que, persistiendo en sus hábitos de robo y salteo, no querían someterse a ninguna disciplina. ${ }^{40}$

\section{Las montoneras populares: hombres «sin Dios ni Ley»}

Neira, el único montonero popular que ayudó a los republicanos, tuvo un fin trágico. ${ }^{41}$ «Neira fue el terror de los tiranos», escribió años más tarde el redactor de El Valdiviano Federal, dejando ver la notoriedad que adquirió el bandido durante su corta campaña militar. ${ }^{42}$ ¿Era ése el pago que se merecían quienes desafiaron a los monarquistas?; ¿Cuántos capitanes de la plebe temieron recibir el mismo castigo? No se puede dar respuestas a estas interrogantes con las fuentes disponibles, pero es evidente que con la ejecución de Neira, la creación de nuevas reclutas, los toques de queda y las restricciones al tránsito de las personas, el gobierno republicano notificó a los 'bandidos y criminales' que, salvo que se sometieran a sus órde-

\footnotetext{
39 Bando de Marcó del Pont, 22 de enero de 1817, Ibidem, 351.

40 Ibidem, XI, 31.

41 León, 1965.

42 El Valdiviano federal, 15 de febrero de 1834.
} 
nes, no tendrían lugar en la nueva Patria. ${ }^{43}$ En ese contexto, se puede entender la reacción de rechazo de algunos cuadrilleros hacia la República, lo que significó, indirectamente, que engrosaran el número de aquellos que combatían contra el nuevo sistema. «Estos jamás pueden prescindir del paisanaje», observó el cabildo de San Fernando cuando apenas comenzaba la nueva guerra, «[es única] la amistad que mutuamente se profesan». ${ }^{44}$ En contraste, los monarquistas entendieron bien el rol que podían jugar los plebeyos en la realización de sus planes; encabezados por el coronel José Ordóñez, desde su baluarte en Talcahuano, su principal preocupación consistió en ganarse la adhesión de los jefes populares.

Ordoñez dirigió a Zapata una carta en que reclamaba los servicios de éste "a la causa de Dios y del Rey", escribió Barros Arana al describir el reclutamiento del montonero José María Zapata, "y encargaba que en nombre de ella llamase a la gente a tomar las armas contra los patriotas. Esa carta circuló de mano en mano entre los rudos e ignorantes campesinos de aquellos lugares, los cuales, sin comprender de lo que se trataba, y en su mayor parte sin poder leer lo que en ella se contenía, corrieron a enrolarse en las guerrillas para defender, decían, la religión amenazada por los herejes". ${ }^{45}$

Desde el momento en que los realistas establecieron contactos con los montoneros, comenzó una ardua etapa política y militar para los líderes republicanos. A la hostilidad que les presentó Concepción, se agregó la sombra de la plebe que, aprovechando las flaquezas de los ejércitos y el desgobierno que creaba la guerra, irrumpía sobre el escenario con su propia carga de latrocinios y asesinatos. «Nada», señaló Barros Arana, «había podido desarraigar los antiguos hábitos de violencia, de depredación y de rapiña, que habían caracterizado a los plebeyos ${ }^{46}$ Los cabildos locales se encontraron una vez más ante la delicada tarea de preservar el orden y someter a la plebe. «Nos vemos rodeados de enemigos domésticos e interiores...», señalaron los ediles del cabildo de San Fernando, reflejando el sentir de otras localidades. ${ }^{47}$ La irrupción de bandas de malhechores demostraba que se producía un reagrupamiento de las fuerzas anti republicanas y

43 Pinto y Valdivia, 2009, 101. 1817.

44 ANMG, 20, 11, Antonio Rey de Velasco y otros a O'Higgins, San Fernando, 3 de abril de

45 Citado en Barros Arana, XI, 138.

46 Ibidem, 31.

47 ANMG, 20, 11, Antonio Rey de Velasco y otros a O’Higgins, San Fernando, 3 de abril de 1817. 
que se formaban las primeras montoneras populares. Comenzaba en esos momentos una nueva era, dominada por la violencia de los grupos subalternos. Frente a esta situación, el gobierno se manifestó con rigor. «He visto la causa iniciada contra José Farfán y otros», escribió O’Higgins, «sus crímenes horrorizan. Cauterio prontísimo exige este cáncer. Sé por los principales vecinos de esta villa que le han envuelto en horrores y amagan con la desolación al vecindario». ${ }^{48} \mathrm{Si}$ bien era de temer que la reacción autoritaria alentara el rechazo popular, el gobierno endureció aún más su posición frente al peonaje. «Apruebo el castigo de azotes y no se canse de perseguir y castigar hasta con la muerte a los malvados, sólo el rigorismo [sic] puede inducir al escarmiento y atraer la serenidad a esos pueblos». ${ }^{49}$ ¿Por qué debían los plebeyos respetar al nuevo gobierno y sumarse a su bando? Esta pregunta no se la hicieron los patriotas, quienes dieron por natural la adhesión del populacho a su causa. Su visión, sin embargo, estaba totalmente errada pues ignoraron el efecto que tendría el colapso de la gobernabilidad en el ánimo de los más audaces jefes de la plebe. Hasta allí, su prontuario incluía asaltos, robos y asesinatos, fugas de las milicias, diezmos impagados, concubinatos y repetidas trasgresiones contra los mandatos eclesiásticos. ${ }^{50}$ Ese había sido su habitual modo de vida, ¿por qué habrían de cambiarlo?

Si se intenta explicar el giro de la plebe, de la apatía inicial a la militancia activa contra el régimen, probablemente uno de sus principales factores fue la represión que desataron los republicanos contra los sujetos más insumisos. No hay datos que permitan reconstruir una estadística de esta represión, pero el tono de la correspondencia oficial refleja una mentalidad autoritaria poco dispuesta a tolerar la criminalidad doméstica. «Vigile Us. sobre ellos con actividad», escribió O’Higgins al teniente gobernador de Talca, «y no cese de castigar y despachar a todos los malvados». ${ }^{51}$ Frente a un gobierno dispuesto a encarcelar o matar a los 'bandidos', fue solamente una cuestión de tiempo para que los plebeyos se alzaran e, indirectamente, favorecieran la causa monárquica. Siguiendo la secuencia de eventos, se descubre que las primeras incursiones de bandas de plebeyos fueron fechadas por las autoridades a fines de mayo de 1817, coincidiendo con la introducción de las primeras medidas represivas. Al respecto, el teniente gober-

\footnotetext{
48 ANMG, 28, 89, O'Higgins al teniente gobernador de San Fernando, 19 de abril de 1817.

49 Barros Arana, XI, 127, O’Higgins a José Santos Astete, 20 de mayo de 1817.

50 Cornejo, 2006.

51 ANMG, 28, 133, O’Higgins al teniente gobernador de Talca, 27 de mayo de 1817.
} 
nador de San Fernando escribió a O’Higgins: «A Vuestra Excelencia le es constante el inminente riesgo en que se halla este pueblo por los muchos salteadores que se han levantado, y que a pesar de mi exigencia, con la que he conseguido la captura de algunos de ellos, no faltan otros que subroguen esta mala semilla...».52 Gradualmente, un contingente importante de plebeyos armados se sumaba a la guerra. Esta acción fue vista por los historiadores como una operación incentivada por los comandantes monarquistas y no como una expresión realmente popular. ${ }^{53} \mathrm{Sin}$ entrar en controversias, lo importante es señalar que la guerra se extendió hacia la población civil, forzando a tomar partido a quienes hasta allí solamente observaron los enfrentamientos con indiferencia o frialdad.

Los monarquistas refugiados en Talcahuano requerían contar con el apoyo popular para combatir con éxito al gobierno central. La tarea de los labradores y peones no sólo consistía en facilitar caballos, ganados y alimentos para sostener la resistencia, sino también en ser cómplices de aquellos que operaban en la campiña. Baqueanos, troperos y pastores, eran cruciales para que las guerrillas lograran sus objetivos. En ese contexto, durante los meses de julio y agosto, comenzaron las operaciones terrestres simultáneas de realistas y montoneros en Chile central. O'Higgins, que tenía sitiado Talcahuano, no se percató que el principal peligro afloraba a sus espaldas bajo la forma de un doble alzamiento: la rebelión armada del peonaje y el desplazamiento de las guerrillas monárquicas hacia su retaguardia. Ambas fuerzas actuaron descoordinadas, pero el desembarco de oficiales realistas en la costa de Maule e Itata facilitó la configuración de un peligroso frente militar que debilitó el esfuerzo gubernamental para terminar con la guerra interna.

\section{Las primeras arremetidas de montoneros y monarquistas en Chile central}

Los jefes monárquicos aprovecharon las acciones militares de líderes plebeyos carismáticos para poner en jaque al poder republicano. A fines de julio, circularon las primeras noticias anunciando que una columna guerrillera devastaba los campos en la región de Maule. «Excelentísimo Señor»,

52 ANMG, 18, 250, José Santiago Palacios a O'Higgins, San Fernando, 21 de mayo de 1817.

53 Villalobos, 1996, 234. 
escribió De la Cruz, «hoy se me ha pedido auxilio de San Carlos, el Parral, y Linares para defenderse y perseguir a una cuadrilla de sesenta hombres acuadrillados al mando de aquel Cruz Palma, que con diez fusileros talan e inquietan aquellos campos...». ${ }^{54}$ A la cabeza de la montonera emergía Cipriano Palma, «con 100 dragones y otros tantos indios bárbaros». La montonera no era mas que eso, una suma de fuerzas irregulares e informales que se unían con el propósito de depredar. Ese mismo día, desde Chillán, el comandante patriota Pedro Arriagada informó:

Las partidas enemigas se aumentan cada día mas: en este partido, el de San Carlos y parte del de Ytata están enteramente sublevados. En Cucha Cucha hay un guerrilla de 15 fusileros; según tenemos noticia han atacado en Ninhue a Don Xavier Solar que venía de Quirihue con 8 fusileros á reunirse con el Teniente Gobernador de San Carlos cuyo resultado ignoramos. En las montañas de Semita y de Cato anda otra partida de cinco fusileros y alguna milicia comandada por Mariano Alarcón y Antonio Pincheira. Por el Roble otra de salteadores junto con Nazario Arias... ${ }^{55}$

Monarquistas y montoneros populares, además de algunos mapuches, eran comandados por sujetos aguerridos que pronto adquirieron fama. El primero que emergió con estos caracteres fue José María Zapata. «El 19 se me dio parte secreto por don Juan Antonio Urrejola que un José María Zapata, sirviente de Don Luis, su hermano, venia con 15 fusileros y otros ladrones a esta villa a saquearla, y asesinar todos los Patriotas...». ${ }^{56} \mathrm{La}$ transformación de un sujeto plebeyo en comandante de partida era un buen reflejo del desorden social que creó la revolución. Como era de esperar, el campo de operaciones elegido por Zapata fue la región de Itata, donde recibió el apoyo de «los inquilinos y sirvientes de la estancia cordillerana de Cato, que ayudarían también a los Pincheira». ${ }^{57}$ Parafraseando a Gabriel Salazar, se puede señalar que la «guerra de guerrillas» de Zapata, «configuró un claro ejemplo de odisea miliciana». ${ }^{58}$ Zapata y Pablo Mendoza, desembarcaron en la costa de Tomé con apenas nueve hombres; Zapata, con cinco montoneros, se dirigió rumbo a Chillán, reclutando en el camino más de doscientos plebeyos armados. Esperaba formar en Chillán un segundo bastión monarquista.

54 ANMG, 21, 118, Luis de la Cruz al director supremo, Talca, 1 de agosto de 1817.

55 ANMG, 23, 202, Pedro Ramón Arriagada al director supremo, Chillan, 1 de agosto de 1817.

56 ANMG, 39, s. f., José María Riquelme al director supremo, San Carlos, 22 de julio de 1817.

Barros Arana lo describe como «antiguo capataz de arrieros», XI, 137.

57 Góngora, 1968, 32.

58 Salazar, 2005, 466. La referencia de Salazar se vincula al mítico Manuel Rodríguez. 


\begin{abstract}
"Se me presentó el enemigo en numero de 20 fusileros y más de 200 hombres de milicias, comandadas por los infantes José María Zapata, Nazario Arias, Félix Muñoz y el mulato de Clemente Lantaño", escribió Arriagada a O’Higgins, “que sin resistencia se introducen hasta la Plaza, dañan todo el pueblo y comienzan a forzar la Cárcel para echar afuera los reos y cometer otros mil excesos en el pueblo, el resultado fue que el enemigo dejó 14 muertos, 11 heridos de gravedad y 17 prisioneros, once fusiles y tercerolas, 3 pistolas, más de 30 caballos ensillados, 10 o 12 lanzas y como seis espadas. La acción duró como cuatro horas, habiendo caído los caudillos Nazario Arias y Juan Pablo Mendoza... al primero lo hice fusilar con dos horas de término y ponerlo a la expectación pública; y el segundo seguirá el mismo destino mañana a las diez del día". ${ }^{9}$
\end{abstract}

Los cuatro sujetos ejecutados en los días posteriores a esta batalla fueron «campesinos de modesta condición». ${ }^{60}$ Seguidos de cerca por los republicanos, los sobrevivientes de la montonera se dirigieron hacia Los Ángeles pero allí sufrieron un nuevo golpe y dejaron algunos prisioneros.

Los tengo bien asegurados en esta cárcel, procesándolos, y mediante sus declaraciones se han tomado cinco aposentadores opuestísimos al sagrado sistema, otro mas desertado del infame punto de Talcahuano Florencio Muñoz, como igualmente dos comandantes de guerrilla salteadores Tiranos opresores desnaturalizados contra los patriotas que lo son el pérfido Domingo Bega (alias el Remalo), y su compañero Santos Orellana (alias el Colorado) que acuadrillados han cometido numerosos, y excesivos crímenes contra el Estado Nacional... Merecen sin perdida de momento ser pasados por las armas los cuatro que se citan... ${ }^{61}$

La captura de los hombres que acompañaban a Zapata causó excitación en el mando republicano. Apenas supo la noticia, el ministro de guerra escribió:

Su Excelencia ha resuelto en el acto mismo mande U. horcar [sic] a todos los diez, y cuantos otros sean cómplices de sus horribles crímenes, sin esperar a más sumario ni formalidades, y dándoles de término solo tres horas desde que se les notifique esta resolución la que, ejecutada, serán descuartizados y colocados sus miembros en las encrucijadas de los caminos y otros parajes donde hayan cometido sus principales crímenes. ${ }^{62}$

59 ANMG, 33, 83, Pedro Arriagada a O’Higgins, Chillán, 3 de agosto de 1817.

60 Barros Arana, XI, 137.

61 ANMG, 23, 105, Juan de Dios Puga a O'Higgins, Cauquenes, 23 de julio de 1817.

62 ANMG, 28, 294, Zenteno al teniente gobernador de Cauquenes, Concepción, 30 de julio de 1817. 
Pero la guerrilla de Zapata y Mendoza no fue la única fuerza que logró infiltrar la retaguardia republicana. Apenas una semana más tarde, se reportaron «las cuadrillas de salteadores que andan por la otra parte del Río Itata, y que estos van aumentando su número con los aplicados a este ejercicio con bocas de fuego...». ${ }^{63}$ Desde San Carlos se informó que una partida de cincuenta «forajidos armados de fusil y alguna milicia» se había fugado hacia los bosques aledaños. ${ }^{64}$ Desde Curicó llegaron informaciones similares.

Se ha levantado en estos contornos un cuerpo de bandoleros que haciendo de cuarenta a cincuenta hombres, entre ellos 16 de tercerola, que asolan a los vecinos del campo con sus salteos, que no hay día que no suceda uno o dos, viéndose muertos por todas partes, y otros muriendo de resultas de las heridas que reciben de estos malvados. ${ }^{65}$

A medida que crecía el contingente anti republicano, se multiplicaron las instrucciones para aplicar sobre los 'bandoleros' todo el peso de la Ley. «Después de un juicio sumarísimo, Us. será el que falle en las causas de estos criminales, dando parte de las ejecuciones que se hicieren...». ${ }^{66}$ Aumentar la represión era un gesto impolítico, pero O'Higgins lo estimó adecuado.

Quiere S. E. que a los dos que tiene U. presos, y a cuantos otros más cómplices aprehendiere, los mande ahorcar en el acto mismo, sin darles una hora de término ni esperar a sustanciación alguna... sólo el terror y la pronta ejecución de los castigos pueden contener los progresos de un mal que amenaza envolvernos. ${ }^{67}$

Con el fortalecimiento de las guerrillas monarquistas y populares, el futuro de la causa republicana parecía estar al borde del barranco. Se enfrentaban dos enemigos, motivo por el cual se aplaudieron con fervor las victorias conseguidas. «No está malo el golpe que Arriagada ha dado en Chillán a los salteadores, bandidos y montoneros que habían formado cuerpo considerable», informó O’Higgins a San Martín. ${ }^{68}$ En su misiva, O’Higgins agregaba: «Bandidos y montoneros, de los que deben haberse ahorcado 18 en

\footnotetext{
63 ANMG, 39, s. f., Manuel José de la Cruz a Zenteno, Florida, 30 de julio de 1817.

64 Idem, José María Riquelme a O’Higgins, San Carlos, 22 de julio de 1817.

65 ANMG, 20, 81, Diego Donoso a Hilarión de la Quintana, Curicó, 12 de agosto de 1817.

66 ANMG, 21, 156, Miguel Zañartu a Luis de la Cruz, Santiago, 14 de agosto de 1817.

67 ANMG, 28, 296, Zenteno al teniente gobernador de Chillán, 3 de agosto de 1817.

68 ABO 8, 33, O’Higgins a San Martín, Concepción, 11 de agosto de 1817.
} 
Chillán, 10 en Cauquenes y tres en la Villa de San Carlos. Sucesivamente cuantos caigan seguirán igual suerte». ${ }^{69}$ En un ambiente marcado por la represión, se juzgó a Andrés Gutiérrez y Juan Contreras, desertores realistas, bajo la acusación de cooperar con los enemigos. Ambos participaron en la batalla de Chacabuco, buscaron refugio en Talcahuano y, desde allí, cabalgaron rumbo a Linares, «con el único objeto de poner en consternación las gentes de los partidos de Chillán, San Carlos y El Parral, entusiasmarlos $\mathrm{y}$ atraerlos a su bando, para que en esta suerte sigan ejecutando sus perniciosas y perjudiciales maniobras...». ${ }^{70}$ Basado en su convicción de que eran agentes de Ordóñez, el comandante de Talca decretó:

Por tanto y para castigar estos escandalosos y execrables excesos relacionados, como corresponde, vengo en aplicarles la pena de muerte que sufrirán abaleados, sentados en banco, vendada la vista, y después de muertos colgados en la horca; cumpliéndose esta sentencia dentro de dos horas de notificados los reos, a quienes se les darán los primeros auxilios de Religión. ${ }^{71}$

Combinar el garrote con la horca siempre ha sido una mala política para atraer adherentes, más aún cuando el desborde de monarquistas y montoneros ya estaba en marcha. Chile central volvía a presenciar el desplazamiento de la violencia; las guerrillas brotaban por doquier, tanto bajo las banderas del rey como bajo los estandartes propios de los hombres «sin Dios ni Ley». ${ }^{72}$ «Haga salir las partidas que estime necesarias», fue la orden que llegó a las tenencias locales, «a expulsar y aprender [sic] esas gavillas de ladrones que perturban la paz de esas jurisdicciones». ${ }^{73}$ Como en toda guerra, las órdenes de escritorio son difíciles de cumplir en los frentes militares. Más aún cuando los comandantes carecían de pertrechos y sus tropas se enfrentaban a hombres que les superaban en entusiasmo, recursos e intrepidez. ${ }^{74}$ Entre los monarquistas comenzó a cundir la audacia a medida que quedaban en evidencia las debilidades de sus enemigos y se hacía notorio el favorable efecto que tenía para su causa la súbita rebelión armada de parte del populacho. O'Higgins no dejó de percatarse de esta peligrosa situación. Súbitamente, se enfrentaba a un enemigo bicéfalo que se despla-

69 Ibidem, 34.

70 ANMG, 21, 145, De la Cruz a Zenteno, Talca, 14 de agosto de 1817.

71 Idem. La confirmación de la sentencia la otorgó O’Higgins el 28 de agosto de 1817, ANMG, 28, 170.

72 ANMG, 39, s. f., De la Cruz a Zenteno, Florida, 13 de agosto de 1817.

73 ANMG, 21, 155, Hilarión de la Quintana a De la Cruz, Santiago, 12 de agosto de 1817.

74 ANMG, 39, s. f., Alcázar a O’Higgins, 29 de julio de 1817. 
zaba a gusto por los escenarios bélicos: monarquistas y montoneros populares. Todos tenían experiencia en las artes de la guerra y constituían un enemigo de magnitud. «Gavilla de desesperados que deseaban una vergonzosa muerte», señaló De la Cruz cuando se refirió a las fuerzas combinadas que asolaron Chillán e Itata. ${ }^{75}$ A esta particular combinación de fuerzas se sumaron, en la región fronteriza del río Bio-bio, los afamados weichafes (guerreros) mapuches, movidos por su adhesión a los tratados establecidos con la monarquía por varios siglos e interesados, coyunturalmente, en vengar la masacre de los lafquenches (costinos) que tuvo lugar a mediados de junio de ese año. ${ }^{76} \mathrm{Su}$ objetivo se dirigió a destruir los bastiones republicanos situados en la ribera sur del río. Así lo demostraron cuando una fuerza de casi dos mil 'indios' arrasó las vecindades del fuerte de Nacimiento y capturó Santa Juana. ${ }^{77}$

La extraordinaria coalición de fuerzas que se alzaban contra la República crecía con el pasar de los días; también aumentaba la fama de sus líderes. Ese fue el caso de Zapata. «Estoy creído que un pícaro Zapata, que se pasó a Arauco con otros de esta Jurisdicción los haya seducido. Como igualmente a los indios...». ${ }^{78}$ Las guerrillas y malones no sólo parecían imbatibles, sino que además reflejaban el fracaso político de la República en la región penquista. «Aún se sostienen algunas cuadrillas de bandidos», reportó O’Higgins a San Martín, «pero la fuerza que he hecho avanzar al interior los aniquilará muy en breve, restableciendo el Orden y la Tranquilidad...». ${ }^{79}$ Estas expresiones de O'Higgins fueron más bien de buenos deseos que un diagnóstico temperado de la situación. Sin adeptos que dieran cobertura a sus partidas, los patriotas se encontraban aislados; de poco sirvió aumentar la represión o poner precio sobre la cabeza de los capitanes de la plebe. «A quienes perseguirá por todos los medios y tomados que sean ellos [Mendoza y Zapata] o sus parciales», se lee en las instrucciones entregadas a los comandantes locales, «los mandará fusilar inmediatamente, sin demora alguna, haciendo se coloquen sus cabezas y miembros en los parajes y caminos donde han cometido sus principales atentados». ${ }^{80}$

75 ANMG, 21, 150, De la Cruz a O’Higgins, 20 de agosto de 1817.

76 León, 2011.

77 ANMG, 49, 110, Agustín López a O’Higgins, Arauco, 12 de septiembre de 1817.

78 ANMG, 39, s. f., Andrés del Alcázar a O’Higgins, Nacimiento, 26 de agosto de 1817.

79 ANMG, 28, 165, O’Higgins a San Martín, 10 de agosto de 1817.

80 ANMG, 49, 235, instrucciones de O'Higgins y Zenteno a José María Íñiguez, Concepción, 1 de agosto de 1817; ver también O’Higgins a Íñiguez, 20 de agosto de 1817, ANMG, 27, 16. 
La impotencia de los republicanos crecía cuando se enfrentaban a un trance bélico inesperado; asimismo, fruto de la desesperación, aumentaron los desaciertos. A fines de agosto proclamaron que se premiaría con 300 pesos a quienes capturaran, «vivo o muerto», a José María Zapata, transformando al «turbulento montonero» en un héroe popular. ${ }^{81}$ Lo significativo es que, a mediados de 1817, los patriotas se enfrentaban a una fuerza militar irregular que no sólo evadía sus persecuciones sino que llegaba hasta los arrabales de las villas con sus desmanes. ¿Qué se podía hacer cuando la población mostraba su adhesión a los guerrilleros? La receta republicana ya se conocía. «Extermine esa parte de la sociedad que tiene en continua inquietud esa parte del reino, intercepta correos y distrae la atención de Vuestra Excelencia». ${ }^{82}$ Con estas palabras, el gobierno resumió su visión respecto de los 'bandidos' que, con sus acciones, favorecían la estrategia de los monarquistas. Informado de la designación de un preboste que se encargaría de 'limpiar' la campaña, O’Higgins escribió:

Ha sido muy bien meditada la medida que Us. ha tomado de mandar competente fuerza al Gobernador de Talca, autorizándole para que nombre un Preboste que, llevando un capellán y un verdugo, haga desaparecer la turba de bandidos de que estaba infestada esta Provincia... con los ejemplares castigos que ya han sufrido estos malvados, parece que no volverán a inquietarnos sus parciales. ${ }^{83}$

De forma simultánea, O’Higgins elaboró un corto Reglamento contra renegados, desertores y montoneros. En su artículo primero, el Reglamento establecía:

Todo hombre sin distinción de fuero estado o clase que sea caudillo o secuaz de la rebelión o montonera en que los pérfidos agentes del Enemigo han tratado de envolver al país, será fusilado a las dos horas de su aprensión, sin más sumario o figura de juicio, que la constancia extrajudicial de su delito, dando cuenta de su ejecución a S. E. ${ }^{84}$

El esfuerzo represivo fue reforzado por los vecinos más acaudalados de las villas, quienes formaron milicias debido a «la escandalosa infestación con que diariamente inundan estos puestos las gavillas de facinerosos

81 ANMG, 28, 303, decreto de O'Higgins, 19 de agosto de 1817.

82 ANMG, 34, 103, Hilarión de la Quintana a O'Higgins, Santiago, 14 de agosto de 1817.

83 ANMG, 33, 94, O’Higgins a Hilarión de la Quintana, Concepción, 27 de agosto de 1817.

84 ANMG, 23, 336, instrucciones al teniente gobernador de Itata, Quirihue, 18 de agosto de 1817. 
y mal entretenidos». ${ }^{85}$ Paulatinamente, la guerra civil entre monarquistas y republicanos adquiría el perfil de una guerra social entre plebeyos y patricios.

Los que subscribimos, por si, y á nombre de otros vecinos del Partido de Puchacay, con el debido respeto a V. E. hacemos presente: que deseando acreditar nuestro interés y celo por el bien público viendo cuán escandalosamente algunos prófugos enemigos de nuestra sagrada causa se unen y asocian, con los salteadores, y facinerosos de la Provincia... hemos acordado formar partidas respetables compuestas de sujetos del mas acendrado patriotismo, y de la mejor conducta para que por distintos puntos del Partido persigan, y aprehendan a los malévolos; y perturbadores de la publica tranquilidad, sin irrogar el menor gravamen al Estado, ni á los particulares, sino a nuestra costa, así en cuanto a manutención como á cabalgaduras... ${ }^{86}$

La incorporación de los vecinos 'nobles' a las partidas que perseguían a los montoneros mejoró la posición militar de los republicanos, pero la movilización de las milicias marcó también un vuelco clasista en la guerra. ${ }^{87}$ De una parte, la gente de fortuna respaldaba la causa republicana, mientras un segmento del populacho se sumaba a la guerra, facilitando la causa monárquica. Lo que militarmente podía ser un acierto, tan sólo profundizaba un error político, pues se hizo más evidente la identificación del nuevo régimen con el patriciado. Empero, con el apoyo de los terratenientes, el gobierno obtuvo algunas victorias militares. Ese fue el caso de la captura del montonero José María Gutiérrez:

Hoy a las 12 se ha puesto en esta cárcel nacional al pérfido traidor José María Gutiérrez, Sargento primero con grado de oficial del Ejército enemigo que en la acción de Rancagua cometió enormísimos crímenes y excesivos excesos [sic] en nuestro Ejército, fugó de la acción de Chacabuco y estaba incógnito oculto en las montañas de la costa Cunquillan y estero de Bare, convocando a muchos para unirse con los bandidos de Chillán y combatir este partido... en toda aquella frontera ha cometido excesivos excesos... ${ }^{88}$

A fines de ese mes, desde Chillán, se anunció la captura de Félix Muñoz, uno de los lugartenientes de Zapata.

85 ANMG, 20, 35, Pedro Maturana a O'Higgins, San Fernando, 13 de julio de 1817.

86 ANMG, 23, 274, Grupo de vecinos a O'Higgins, Minas de la Florida, 12 de agosto de 1817.

87 ANMG, 28, 304, O’Higgins al teniente gobernador de Puchacay, 19 de agosto de 1817. O'Higgins al teniente gobernador de Los Ángeles, 21 de agosto de 1817, Ibidem, 308; O'Higgins al teniente gobernador de Itata, 23 de agosto, de 1817, Ibidem, 316; Arriagada a O’Higgins, Chillán, 3 de agosto de 1817, ANMG, 33, 83.

88 ANMG, 23, 114, Juan de Dios Puga a O’Higgins, Cauquenes, 17 de Agosto de 1817. 
Félix Muñoz principal agente de José María Zapata abusando de la benevolencia y conmiseración con que VE les ha mirado ofreciéndoles perdón por el horrendo crimen de conspirar contra la seguridad del Estado. Este infame no solo procuraba seducir sino que escandalosamente tenía reuniones y juntas nocturnas en su casa... Félix Muñoz ha pagado hoy en el cadalso con la vida los delitos cometidos... ${ }^{89}$

La captura de Gutiérrez y Muñoz fue una seria pérdida para la montonera de Zapata. Pero las malas noticias no llegaron sólo ahí. Dos semanas más tarde, se produjo la captura de Justo Guajardo, acusado de apoyar «a los mas delincuentes que acompañaron al pérfido José María Zapata, dándoles a estos un papel como de seguros de quedar ya perdonados de su delincuencia...»..$^{90}$ Las montoneras comenzaban a sufrir derrotas y sus seguidores eran llevados al cadalso.

"En ocho días del mes de noviembre, y a las diez del día, se conducieron [sic] Pedro
Candia y Severino Caamaño al patíbulo del último suplicio", rezaba un documento de
comienzos de diciembre, "donde al furor de seis balas entregaron el último suspiro.
Y colgados sus cadáveres en la horca a la expectación pública, fueron descolgados a
las cinco y media de la tarde, y por el verdugo se les mutiló, despachando sus cuer-
pos a la caridad y las cabezas al lugar donde designa el Fiscal y se conforma el
Auditor de Guerra". ${ }^{91}$

Los castigos eran cada vez más crueles, pero el alzamiento popular no amainó. ${ }^{92}$ De otra parte, se produjo una intensificación de los ataques mapuches contra los fuertes fronterizos y se registró una mayor actividad militar de los monarquistas en Concepción. «Solo conseguirán incendiar», escribió O’Higgins, «las villas, casas, haciendas y chozas de los lugares que están, por su distancia, indefensas y asesinar como lo están ejecutando, a los inermes habitantes de los campos. ¡Malvados! Sus crímenes no quedarán impunes». ${ }^{93} \mathrm{~A}$ mediados de octubre, una fuerza de 2.000 'indios y guerrilleros' atacó Santa Juana y arrasó Nacimiento, siguiendo su propia estrategia de acoso contra los emplazamientos republicanos. Fue en ese instante cuando entró en la escena, encabezando una fuerza compuesta por monarquistas, plebeyos y mapuches, quien se convertiría en uno de los montoneros más emblemáticos de la época: Pablo Pincheira. Por segunda

89 Ibidem, 212, Arriagada a O'Higgins, Chillan, 3 de septiembre de 1817.

90 Ibidem, 361, Manuel González al director supremo, 21 de septiembre de 1817.

91 ANMG, 7, 193, notificación de la muerte de Pedro Candia y Severino Caamaño, Penco, 8 de noviembre de 1817 .

92 ANMG, 8, 46, O’Higgins a San Martín, Concepción, 1 de octubre de 1817.

93 ABO 8, 48, O’Higgins a San Martín, Concepción, 18 de octubre de 1817. 
vez, surgía un caudillo capaz de aglutinar las diversas fuerzas que luchaban contra la República. ${ }^{94}$ Esta faceta del nuevo jefe fue visualizada tempranamente por los republicanos, quienes veían colapsar su autoridad en medio del fárrago de la guerra informal.

Sírvase U. S. remitirme con la mayor vigilancia la mayor fuerza posible que tuviere a su mando para combatir la partida del malvado Pincheira que aplica todas sus miras a imitar la conducta de Zapata, y lo peor es que diariamente se va engrosando hasta haber formado fuerza muy suficiente para incomodarnos. El cáncer se va propagando con un movimiento progresivo, y con tal rapidez que ya nos mantiene en una continua molestia. ${ }^{95}$

Hacia fines de 1817, los republicanos no sólo perdían la guerra sino también el apoyo de la población civil. Los exitosos ataques contra las plazas fronterizas y el asedio en las localidades más pequeñas demostraron que los monarquistas ganaban terreno, mientras cundía la desesperación en las filas del gobierno. ${ }^{96}$ Este último insistió en calificar de ladrones a los guerrilleros populares, pero es difícil pensar que los montoneros lucharan sólo por el interés del botín. ${ }^{97}$ La guerra, que hasta allí parecía favorecerles, sorprendió a los hombres de O’Higgins atrincherados en los fuertes. ${ }^{98}$ Batir a los montoneros era el primer objetivo militar de las partidas republicanas; impedir que ganasen un bastión fronterizo, desde el cual pudiesen organizar sus ataques, era el plan estratégico a más largo plazo. ${ }^{99}$ La persecución de las columnas de Pincheira tuvo algún éxito pues, a fines de octubre, se logró ubicar su campamento.

"Habiendo sabido el veinte del actual la tirana opresión con que se hostilizaba este Partido y el de San Carlos por el pérfido, inicuo, infame traidor Antonio Pincheira con trescientos y más individuos que formaban una gavilla de bandidos que arrasaban las haciendas, salteando y degollando a su arbitrio á los decididos á nuestra sagrada causa", informó en un parte Juan de Dios Puga a O'Higgins, "después de haber combinado mi urgente movimiento á remediar los males que amenazaban á las armas del Estado... y mediante las activas providencias que libré a las orillas del río de Nuble, sobre la hacienda de Cato, madriguera de iniquidades contra nuestra libertad, logré

94 Pinto, 2000, 54. 1817.

95 ANMG, 22, 131, José María Riquelme a Juan de Dios Puga, San Carlos, 20 de octubre de

96 Ibidem, 134, Juan de Dios Puga a Francisco Montes, Cauquenes, 20 de octubre de 1817.

97 Barros Arana, XI, 136.

98 ANMG, 21, 244, Francisco Montes al director supremo, Talca, 3 de octubre de 1817.

99 Ibidem, 241v., Francisco Montes al director supremo, Talca, 24 de octubre de 1817. 
prender siete de los que fraguaban la opresión y tomadas sus declaraciones con la brevedad que exigía la materia, el veinte y cuatro pasé por las armas con termino de dos horas á Santiago Mera y Sabino Anrriques, espías de quienes tomé noticias que el enemigo se hallaba situado y fortalecido con doce fusiles y cinco pares de pistolas en la Hacienda de Bureu, sita en el Partido del dominio de Doña Mercedes Riquelme....". ${ }^{100}$

La posibilidad de destruir a los Pincheira se convirtió en la orden del día para los republicanos, pero los esfuerzos fueron inútiles. ${ }^{101}$ Como hombres que huían de la muerte, Pincheira y lo que quedó de su montonera iba dejando tras de sí una estela de sangre y pavor. Su intención era llegar hasta Talcahuano.

"Los esfuerzos del enemigo para divertir nuestras tropas y hostilizarnos", informó O’Higgins a San Martín, "no sólo se habían propagado en la Alta Frontera y sus costas, sino que también se extendían a las montañas de Tucapel y Chillán, donde habían logrado ya introducir un número considerable de armas y municiones con que obraban reunidos más de 200 bandidos, incendiarios y ladrones". ${ }^{102}$

Con esas palabras, resumió O'Higgins el resultado de las primeras campañas contra los montoneros populares que, de modo indirecto, favorecieron el resurgimiento del enemigo monárquico. Al escribir esas líneas no imaginó que, apenas un mes más tarde, sus regimientos deberían abandonar el sur de Chile, perseguidos por las fuerzas del general español Mariano Osorio. La guerra con los hombres del rey terminó en los llanos de Maipú en abril de 1818. Ese fue el momento más glorioso para los republicanos, pero también marcó el comienzo de una nueva guerra de la plebe fronteriza, encabezada por el propio Pincheira y engrosada por caudillos de la talla de Vicente Benavides, los hermanos Prieto, el cura Ferrebú, el coronel Francisco Sánchez y el comerciante Manuel Pico. ${ }^{103}$ A ellos se sumaron miles de renegados y fugitivos monarquistas, además de poderosos contingentes de mapuches provenientes de las tribus nagche (abajinos), nguluche (arribanos) y lafquenches (costinos), además de los pehuenches, quienes, globalmente, siguieron su estrategia autonomista y aprovecharon la debilidad de los criollos para restablecer su señorío en la

100 ANMG, 23, 225, Juan de Dios Puga a O’Higgins, Chillan, 27 de octubre de 1817.

101 ANMG, 39, s/f., José María Riquelme a O’Higgins, San Carlos, 30 de octubre de 1817; Manuel González al director supremo, Quirihue, 2 de noviembre de 1817, ANMG, 23, 377.

102 ANMG, 28, 339, O'Higgins a San Martín, 1. ${ }^{\circ}$ de noviembre de 1817.

103 Vicuña, 1955; Mackenna, 1972; Guevara, 1910. 
frontera. Comenzó así la Guerra a Muerte, un suceso que, por su complejidad, debe ser investigado de modo más acucioso para precisar su real impacto en la historia de Chile.

\section{La guerra popular inconclusa en la gestación de la República}

Apenas habían transcurrido dos horas después de la batalla, los huasos de la región (que durante todo el tiempo estuvieron observando la lucha fuera de la línea de fuego), se dedicaron a despojar a los muertos y moribundos, dejando desnudos a muchos de aquellos, retirándose enseguida con el botín. Yo vi a un hombre que corría con una presa considerable, consistente entre otras cosas, en una docena de fusiles, atravesados sobre el arzón de la silla... ${ }^{104}$

Ese hombre, descrito de un modo tan expresivo por el viajero inglés Samuel Haigh en el crepúsculo de la batalla de Maipú, como cientos o miles más, fue uno de los protagonistas de la historia posterior del bandidaje que marcó en su nacimiento al sistema republicano en Chile. En 1821, casi cuatro años más tarde, O’Higgins señaló que Benavides contaba con el apoyo de las reducciones mapuches del Gulumapu y sumaba el apoyo de «la multitud de facinerosos de todo el pays que se le han refugiado...». ${ }^{105}$ Sus fuerzas, según Barros Arana, estaban formadas por «milicianos rudos de la frontera, fanatizados en nombre de la religión por la causa del rey, y a favor de una guerra en que habían desarrollado el hábito del pillaje...». ${ }^{106}$

El relato oficial ha insistido en describir a los montoneros populares como combatientes espontáneos que, sin doctrina política, aprovecharon la crisis de gobernabilidad que afectó al país para cometer desmanes; pero es evidente que fueron algo más que oportunistas y meros ladrones. Los montoneros se mostraron proclives a la autonomía social, siguiendo la tradición de marginalidad de los antiguos cuatreros y gavilleros, y rechazaron el monopolio del poder que ejercían los terratenientes y mercaderes en el nuevo régimen. Es cierto que aún falta por descubrir la documentación que permita reconstruir su consciencia política, pero la ausencia de esos datos no es razón para aceptar, sin críticas, el relato de la Independencia; interesados en reducir el protagonismo de la plebe, los historiadores liberales del siglo XIX - la mayor parte de ellos ministros, intendentes y funcionarios

104 Haigh, 80.

105 ANMG, 73, s. f., O'Higgins a Ignacio Zenteno, 10 de septiembre de 1821.

106 Barros Arana, 109. 
del Estado- sentaron un perfil empobrecido, escuálido y patético de quienes fueron el tercer partido combatiente de la guerra. Posteriormente, se procuró ver en ellos a bandidos sociales ${ }^{107}$ Lo que no se dice es que los 'malditos huasos', como les denominó Carrera en su Diario, se levantaron armados contra quienes les habían reclutado a la fuerza para luchar contra la monarquía. ${ }^{108}$ Los huasos, convertidos en guerrilleros, no eran ya la mera comparsa que aplaudía a los jefes revolucionarios, que recogía las monedas que arrojaban a su paso o que simplemente acudía a las órdenes de sus patrones. ${ }^{109}$ No se pretende decir que todo el peonaje chileno se alzó, sino señalar que un importante segmento de la plebe — la ausencia de fuentes impide ser más preciso- resistió al nuevo régimen, uniéndose a los mapuches y a los hombres del rey. La espontánea 'alianza' no fue de índole doctrinaria sino pragmática; no estaba unida por un discurso común ni operaba bajo un mando único; lo que les cohesionaba era su deseo compartido de impedir el triunfo republicano. Lo que sucedió entre 1810 y 1820 fue un hecho inédito en la historia de Chile. Por primera vez, después de tres siglos de existencia, se producía un levantamiento armado contra el Estado. ¿Se trató del inicio de una guerra social o fue una mera rebelión dentro de la rebelión emancipadora? La ausencia de datos impide dar una respuesta decisiva a esta interrogante, pero la investigación más acuciosa de las fuentes debiera proporcionar valiosos datos para entender el rol de la plebe de esos días.

Recibido el 14 de julio de 2011 Aceptado el 30 de septiembre de 2011

\section{Bibliografía}

Araya Espinoza, Alejandra: Ociosos, vagabundos y mal entretenidos en Chile Colonial, Santiago, Centro de Investigaciones Diego Barras Arana, 1999.

Barros Arana, Diego: Historia General de Chile, 17 vols., Santiago, 2da. edición, 2001.

Bengoa, José: Historia del pueblo mapuche siglos XIX y XX, Santiago, Ediciones Sur, 1985.

107 Salinas, 1986, 58; Contador, 1998, 189.

108 Carrera, 1976, 303.

109 Pinto y Valdivia, 2009, 34. 
Carrera, José Miguel: Diario, 1810-1814, Santiago, Editorial Quimantú, 1973.

Cartes, Armando: Concepción contra Chile. Consensos y tensiones regionales en la Patria Vieja (1808-1811), Santiago, Centro de Estudios del Bicentenario, 2010.

Casanova, Holdenis: «Entre la ideología y la realidad: la inclusión de los mapuche en la nación chilena (1810-1830)», Revista de Historia Indígena (citado en adelante $R H I$ ) 4, Santiago, 2000.

Cogdell, Sam: «Criollos, gachupines y 'plebe tan en extremo plebe': retórica e ideologías criollas en Alboroto y Motín de México de Sigüenza y Góngora», en Moraña, Mabel (ed.), Relecturas del Barroco en Indias, New Hampshire, Hannover, 1994, 245-279.

Collier, Simon: Ideas y política de la Independencia chilena, 1808-1833, Santiago, Editorial A. Bello, 1977.

Contador, Ana María: Los Pincheira. Un caso de bandidaje social. Chile 18171832, Santiago, Bravo y Allende Editores, 1998.

Cornejo, Tomás et al: La Pena de muerte en Chile colonial, Santiago, RIL, 2003.

De Salas, Manuel: «Oficio de la Diputación del Hospicio al Excmo. Señor don Luis Muñoz de Guzmán, gobernador y capitán general del reino, en que se proponen medidas para arbitrar recursos con qué sostener el establecimiento» (1804), en Grez, Sergio (rec. y estudio crítico): La cuestión social en Chile. Ideas, debates y precursores, 1804-1902, Santiago, Dirección de Bibliotecas, Archivos y Museos-Centro de Investigaciones Diego Barros Arana, 1995, 45-50.

Encina, Francisco A.: Historia de Chile, desde su prehistoria hasta la revolución de 1891, Santiago, Editorial Ercilla, 1984, 15 volúmenes.

Eyzaguirre, Jaime: Ideario y ruta de la emancipación chilena, Santiago, Editorial Universitaria, 1957.

Fernández, Marcos: «Justicia colonial, indulto y sujeto popular. El hombre frente al perdón y la justicia. Chile, siglo XVIII», Estudios Coloniales 1, Santiago, 2000, 75-110.

Fisher, John; Kuethe, Allan y McPharlane, Anthony (comps.): Reform and Insurrection in Bourbon New Granada and Perú, Baton Rouge, Louisiana University Press, 1990.

Gallardo, Viviana: «Héroes indómitos, bárbaros y ciudadanos chilenos: el discurso sobre el indio en la construcción de la identidad nacional», RHI, 5, Santiago, 2001, 119-134.

Ginzburg, Carlos: El queso y los gusanos. El cosmos según un molinero del siglo XVI, Barcelona, Atajos, 1981.

Goicovich, Igor: «Conflictividad social y violencia colectiva en Chile tradicional. El levantamiento indígena y popular de Chalinga (1818)», Revista de Historia Social y de las Mentalidades, 4, Santiago, 2000, 59-70. 
Góngora, Mario: «Vagabundaje y sociedad fronteriza en Chile (siglos XVII a XIX)», Cuadernos del Centro de Estudios Socioeconómicos, Santiago, Facultad de Ciencias Económicas, Universidad de Chile, 1968.

Gruzinski, Serge: Man-Gods in the Mexican Highlands. Indian Power and Colonial Society, 1520-1800, Stanford, Stanford University Press, 1989.

Guerrero Lira, Cristián: La contra-revolución de la Independencia en Chile, Santiago, Editorial Universitaria/Centro de Investigaciones Diego Barrios Arana, 2002.

Guha, Ranahit: Las voces de la historia y otros estudios subalternos, Barcelona, Editorial Crítica, 2002.

Haigh, Samuel: Viaje a Chile en la época de la Independencia, 1817, Santiago, Editorial del Pacífico, 1955.

Hobsbawm, Eric: Rebeldes primitivos. Estudios sobre las formas arcaicas de los movimientos sociales en los siglos XIX y XX, Barcelona, Editorial Crítica, 2001.

Jocelyn-Holt, Alfredo: La Independencia de Chile. Tradición, Modernización y Mito, Madrid, MAPFRE, 1992.

León, Leonardo: «Reclutas forzados y desertores de la Patria: el bajo pueblo chileno durante la guerra de la Independencia, 1810-1830», Revista Historia, 35, Santiago, 2002, 251-297.

León, «"De muy malas intenciones y de perversas entrañas...”. La imagen de la plebe en los preámbulos de la independencia de Chile, 1800- 1810», Colonial Latin American Historical Review, 14/4, Albuquerque, New México, 2007, 337-368.

León, «El difícil dilema de sobrevivir entre dos patrias: el bajo pueblo chileno entre Chacabuco y Maipú, 1817», Cuadernos de Historia, 29, Santiago, 2008, 33-66.

León, «La deserción durante la Guerra de la Independencia de Chile, 1818-1820», Cuaderno de Historia Militar, 5, Santiago, 2009, 75-102.

León, «La República patricia frente al abismo plebeyo: Chile, 1818», Tiempo Histórico, Santiago, 2010, 107-132.

León, O'Higgins y la cuestión mapuche, 1817-1818, Santiago, Akhilleus, 2011.

León, René: El bandido Neira, Santiago, Editorial Orbe, 1965.

Lynch, John: The Spanish American Revolutions, 1808-1826, London, 1973.

McFarlane, Anthony: «Rebellions in late Colonial Spanish America: A Comparative Perspective», Bulletin of Latin American Research, 14, 3, London, 1995, 313-338.

Marimán, Pablo et al: ¡...Escucha winka....! Cuatro ensayos de Historia Nacional Mapuche y un Epílogo sobre el futuro, Santiago, LOM Ediciones, 2006.

Meza, Néstor: La conciencia política chilena durante la monarquía, Santiago, Universidad de Chile, Facultad de Filosofía y Letras y Educación, 1958. 
Minchon, Martin: The people of Quito, 1690-1810. Change and unrest in the Underclass, Boulder Co., Westview Press, 1994.

O'Phelan, Scarlett: Un siglo de rebeliones anticoloniales. Perú y Bolivia, 17001800, Cuzco, Centro Bartolomé de Las Casas, 1988.

O'Phelan, La gran rebelión en los Andes: de Tupac Amaru a Tupac Catari, Cuzco, Centro Bartolomé de las Casas, 1995.

O’Phelan, «La construcción del miedo a la plebe en el siglo XVIII a través de las rebeliones sociales», en Rosas Lauro, Claudia (ed.): El Miedo en el Perú (siglos XVI al XX), Lima, Pontificia Universidad Católica del Perú, 2005, 123-138.

Phelan, John L.: The People and the King: The Comunero revolution in Colombia, 1781, Madison, University of Wisconsin Press, 1978.

Pinto, Jorge: De la inclusión a la exclusión. La formación del Estado, la nación y el pueblo mapuche, Santiago, Universidad de Santiago de Chile, 2000.

Pinto Vallejos, Julio y Valdivia Ortiz de Zárate, Verónica: ¿Chilenos Todos? La construcción social de la nación (1810-1840), Santiago, Editorial LOM, 2009.

Quintero, Inés: «Sobre la suerte y pretensiones de los pardos», en Frasquet, Ivana (coord.): Bastillas, Cetros y Blasones. La independencia en Iberoamérica, Madrid, Fundación MAPFRE, 2006, 327-346.

Rojas, Mauricio F.: Las voces de la justicia. Delito y sociedad en Concepción (1820-1875): Atentados sexuales, pendencia, bigamia, amancebamiento $e$ injurias, Santiago, CIDBA, 2008.

Salazar, Gabriel: Labradores, peones y proletarios. Formación y crisis de la sociedad popular chilena, Santiago, SUR, 1985.

Salazar, La historia desde abajo y desde adentro, Santiago, Facultad de Artes, Universidad de Chile, 2003.

Salazar, Construcción de Estado en Chile (1760-1860). Democracia de los pueblos. Militarismo ciudadano. Golpismo oligárquico, Santiago, Editorial Sudamericana, 2005.

Salinas, Maximiliano: «El bandolero chileno del siglo XIX. Su imagen en la sabiduría popular», Araucaria de Chile, 36, Madrid, 1986, 57-76.

Serulnikov, Sergio: Conflictos sociales e insurrección en el mundo colonial andino. El norte de Potosí en el siglo XVIII, México, FCE, 2006.

Stern, Steve (comp.): Resistance, rebellion and Consciousness in the Andean Peasant World, 18th to 20th Centuries, Madison, University of Wisconsin Press, 1987.

Talavera, Manuel A.: «Revoluciones de Chile», Colección de Historiadores y Documentos relativos a la Independencia de Chile, Santiago, 1900-1954, 3.

Terán, Marta y Serrano, José Antonio (comps.): Las Guerras de Independencia en la América Española, Michoacán, Universidad Michoacana de San Nicolás de Hidalgo, 1999. 
Thompson, E.P.: «La economía moral de la multitud en la Inglaterra del siglo XVIII», en Thompson, Obra Esencial, Barcelona, Editorial Crítica, 2002, 363-433.

Valencia Llanos, Alonso: «Elites, burocracia, clero y sectores populares en la independencia quiteña (1809-1812)», Procesos: Revista Ecuatoriana de Historia, 3, 3, Quito, 1992, 34-55.

Van Young, Eric: The other rebellion. Popular Violence. Ideology and the Mexican Struggle for Independence, 1810-1821, Stanford, Stanford University Press, 2001.

Vicuña Mackenna, Benjamín: La Guerra a Muerte, Santiago, Editorial Francisco de Aguirre, Tercera Edición, 1972.

Villalobos, Sergio: «El bajo pueblo en el pensamiento de los precursores de 1810», Anales de la Universidad de Chile, 120, Santiago, 1960, 36-48.

Villalobos, Tradición y reforma en 1810, Santiago, Editorial Universitaria, 1961.

Villalobos, Vida fronteriza en la Araucanía: el mito de la guerra de Arauco, Santiago, Editorial Andrés Bello, 1996.

Wolf, Eric R.: Europa y la gente sin historia, México, FCE, 2009. 